\title{
Overview of Renal Transplantation in the United States
}

\section{Chase Cavayero and Pran M Kar}

Department of Nephrology, Veterans Adminstration, USA

"Corresponding author: Pran M. Kar, Department of Nephrology, Veterans Adminstration, 5201 Raymond Street, Rm 1006, Orlando, Flroida 32803, USA, Tel: 014076291599; Fax: 4078723990; E-mail: pran.kar@va.gov

Rec date: Jul 03, 2020, Acc date: Jul 08, 2020, Pub date: Jul 10, 2020

Copyright: (C) 2014 Cavayero C, et al. This is an open-access article distributed under the terms of the Creative Commons Attribution License, which permits unrestricted use, distribution, and reproduction in any medium, provided the original author and source are credited.

\begin{abstract}
Renal transplants have been performed in US since 1954. Survival rates have improved with new techniques and immunosuppressants. The 5 year survival rate of cadaveric and living related is $66 \%$ and $78 \%$ respectively. Renal transplant offers a cost effective and better quality of life. Since 2001 the number of live kidney donors has surpassed cadaveric donors in United States. As a society we need to encourage organ donation via education and outreach programs.
\end{abstract}

Keywords: Renal transplants; Immunosuppressants; Live kidney donors; Cadaveric donors; Organ donation; Education and outreach programs

\section{Background}

Joseph Murray performed the first renal transplant in the United States in 1954 [1]. Although the donated kidney was rejected soon after the procedure, this breakthrough opened many doors in the field of transplant surgery [2]. Soon after, a group of surgeons from Boston successfully transplanted a kidney in identical twins, to eliminate a potential immune response [3]. This attempt proved to be visionary as the kidney lasted a full 8 years after the transplant.

Although pioneering surgeons faced great challenges in their initial attempts, these procedures laid the groundwork for modern day advances. The changes in surgical technique, improved tissue typing, and the advent of immunosuppressive medications have allowed renal transplants to become the gold standard for patients with end stage renal disease in the United States. Such transplants not only offer a cost effective alternative to long-term dialysis [4], but also lead to a better quality of life [5].

Forty six years after the first successful kidney transplant was performed, more than 200,000 kidney transplants have been reported at transplant centers throughout the United States [6]. The trend towards increased utilization of kidney transplant should continue as survival rates improve. Compared with the 5 year cadaveric and living donor graft survival rates reported for kidney transplants 25 years ago, today's results of $66 \%$ and $78 \%$ are encouraging [6]. Notably, since 2001, the number of live kidney donors has surpassed the number of cadaveric donors in the United States [7].

\section{Procedure}

Surgical approaches to renal transplantation in the United States are straightforward. After the donor kidney is harvested, the vessels are trimmed to the appropriate size to allow correct anastomosis. Next, an incision is made to expose the iliac vessels. The renal vein and artery are then anastomosed to the external iliac vein and artery respectively [8]. Finally, the kidney is placed in the iliac fossa in order to allow for simple biopsy in the case of rejection [8]. In athletes, the kidney is often placed deeper within the abdomen to protect it from trauma associated with contact injuries. Most often, the diseased kidneys are left within the abdomen to avoid additional complications [9]. However, in the case of polycystic kidney disease and uncontrolled hypertension, native kidneys may be removed.

Donor safety must be a priority in living donor kidney transplantation. A thorough medical evaluation is needed to ensure adequate donor health pre and post surgery. Additionally, renal function must be observed over time. Prior to surgery, donors are screened for any absolute contraindications including uncontrolled hypertension, diabetes, BMI greater than 35, and nephrolithiasis with high likelihood of recurrence [10]. In hereditary renal disease, genetic studies must also be analyzed in order to minimize the risk of recurrence.

If the donor' $\mathrm{s}$ health and kidney function are adequate, nephrectomy can be performed using several different techniques. Open, laparoscopic and robot-assisted techniques are currently available for donor nephrectomy. Minimally invasive laparoscopic and robotic techniques have become more prevalent. They minimize the drawbacks of open donor nephrectomy, making it more appealing to prospective donors [11]. These methods tend to reduce hospital stay, have shorter operative times, and longer warm ischemia times, thus allowing the donor a quicker return to work without compromising graft function [12].

\section{Immunosuppression}

Since the 1950' s, physicians have recognized the need for immunosuppression in renal transplants [2]. Since then, various techniques and medications have been used to encourage successful acceptance of donor kidneys. However, these techniques have come at the expense of transplant tolerance. Transplant tolerance is a state in which there is a lack of a destructive immune response by the recipient toward the donor organ, in the absence of maintenance immunosuppression, and with a fully intact immune system [13].

To this point, the medical field has not been able to achieve "true tolerance" as immunosuppression regimens have expanded in order to accommodate changing protocols. Exact treatment protocols differ throughout transplant centers within the field. However, the primary 
goal of therapy is to control the CD4+ T-cell reaction believed to be responsible for initiating the rejection response in transplant procedures [14]. Current regimens most often use a "triple therapy" consisting of a glucocorticoid, a calcineurin inhibitor (CNI), and an antiproliferative agent. Doing so allows for adequate immunosuppression while limiting toxicity associated with high-doses of a single agent [15]. Interestingly, some centers have dropped corticosteroid use entirely due to increased risk of infection, increased frequency of hypertension, hyperlipidemia and glucose intolerance [16].

There is consensus among transplant centers through controlled randomized trials and meta-analysis that induction therapy with biologic antibodies helps in reducing rejection and failure [17,18]. Recently, the costimulation blocker belatacept, which inactivates a receptor on $\mathrm{T}$ cells, has shown promise as a potential alternative to more traditional "triple therapy" [19].

Still other techniques for controlling graft rejection include the use of mesenchymal stromal cells (MSC). Such cells display the ability to inhibit the proliferation of alloactivated recipient T-cells and protect against ischemia/reperfusion injury [20-22]. Further development of MSC technology, could provide patients with treatment options similar to a "true" immunological transplant tolerance.

Despite progress in controlling the cell-mediated immune response, antibody mediated rejection (AMR) poses a significant challenge to short and long-term graft survival in kidney transplantation [23]. Specifically, growing populations of sensitized patients present great challenges in avoiding humoral transplant rejection. Although treatments such as monoclonal antibodies, intravenous immunoglobulin (IVIG) and plasmapheresis (PP) have been developed for this problem, AMR remains a difficult issue to address.

Though formidable challenges still exist, these advancements represent the significant progress made in immunosuppressive techniques over the past 50 years of transplant surgery (Table 1).

\begin{tabular}{|l|l|l|}
\hline $\begin{array}{l}\text { Immunosuppressive } \\
\text { Agent }\end{array}$ & $\begin{array}{l}\text { Year } \\
\text { Introduced }\end{array}$ & Category \\
\hline Predisone & 1955 & Glucocorticoid \\
\hline Azathioprine & 1968 & Antiproliferative \\
\hline Cyclosporine mofetil & 1995 & Calcineurin Inhibitor \\
\hline Tacrolimus & 1983 & Calcineurin Inhibitor \\
\hline $\begin{array}{l}\text { Mycophenolate } \\
\text { (MMF) }\end{array}$ & 1998 & IL-2 Receptor Antibody \\
\hline Basiliximab & 1999 & Antiproliferative \\
\hline Sirolimus & 2011 & Costimulation blocker \\
\hline Belatacept & &
\end{tabular}

Table 1: Immunosuppressive treatment

\section{Survival Rates of Graft (Living vs. Cadaveric Comparisons)}

Renal transplant has long been associated with less mortality than patients on dialysis awaiting transplantation [24]. However, due to limited donor organs, cadaveric and living donors are both used regularly in the United States. A shortage of cadaver kidneys relative to increasing demand has led to a remarkable rise in transplantation from living donors [25].

This trend may be beneficial, as living-related donor (LRD) renal allografts have been recognized to have a higher overall graft survival than cadaver donor transplants [26-28]. Proposed mechanisms for this disparity include inflammatory injury around the time of brain death [27] and delayed graft function associated with cadaveric kidneys [29]. For these reasons, living-donor transplantation is encouraged as the first option for children with end-stage renal disease [30]

Further advantages to live donor transplantation include the need for less immunosuppression [31], and desensitization techniques that can overcome complications such as HLA disparity and ABO or crossmatch incompatibility [32]. Additionally, modern imaging modalities may be used on living donors to achieve greater long-term success. In particular, CTA and MRI are being utilized to assess the renal vasculature of living related donor kidneys [33,34]. Also important, live donation can allow transplantation to occur before initiation of renal replacement therapy.

While live kidney donation has proven to be superior in many ways, there is still a place for cadaveric donations. It seems improved harvesting techniques and early grafting of the cadaveric kidneys could allow similar results to living kidney transplant [35]. More research must be done to create practice guidelines that will improve cadaveric transplants in the future.

\section{Discussion on Donation}

Often live donors are unable to donate to the intended recipient because of difficulty in immuncompatability [28]. Recently, kidney exchange, in which incompatible patient donor pairs are matched, has facilitated transplantation of kidneys from living donors [29]. However, problems still arise when trying to obtain adequate numbers of cadaveric kidneys, as there is an upper limit to the number of such kidneys available for transplantation [35]. To become a deceased donor an individual must have registered with the department of motor vehicles or had his/her organs donated by the next of kin after death.

For years, researchers have been studying methods that will yield greater organ donor participation rates. To alleviate this problem, economists have produced numerous theoretical organ-sale markets. However due to ethical concerns, it is unlikely that any of these will be approved for use in the United States. Another interesting approach to raise organ donor rates involves the "reciprocity policy." Under this policy, those who have donated organs would be granted preference in the event that they later required a transplant [36].

Another possible solution is a move towards presumed consent. In the United States, we currently employ a system of expressed consent, essentially forbidding organ transplant unless expressed directly in advance. However, other nations (notably Belgium), have improved donor rates using a presumed consent approach [37]. In this system, patients are presumed to be organ donors unless otherwise noted. In this way, patient autonomy is still respected, but the number of organs available for donation is increased.

As a society, it seems that we are headed in the direction of increased organ donation. However, more must be done to increase participation in donor registries. Greater efforts should be put forth towards giving potential donors more opportunities to register. 
Further, the lack education surrounding live donation must be addressed before rates improve significantly. Outreach campaigns, particularly amongst minority populations may prove to be useful be in improving donation rates [36]. In taking these steps we can provide additional chances for potential donors to consider donating an organ that may one day, save a life.

\section{References}

1. Murray JE (1982) Reflections on the first successful kidney transplantation. World J Surg 6: 372-376

2. Legendre Ch, Kreis H (2010) A tribute to Jean Hamburger's contribution to organ transplantation. Am J Transplant 10: 2392-2395.

3. Guild WR, Harrison JH, Merrill JP, Murray J (1955) Successful homotransplantation of the kidney in an identical twin. Trans Am Clin Climatol Assoc 67:167-173.

4. Laupacis A, Keown P, Pus N, Krueger H, Ferguson B, et al. (1996) A study of the quality of life and cost-utility of renal transplantation. Kidney Int 50:235-242.

5. Fisher R, Gould D, Wainwright S, Fallon M (1998) Quality of life after renal transplantation. J Clin Nurs 7: 553-563.

6. Cecka JM (1999) The UNOS Scientific Renal Transplant Registry--2000. Clinical transplants 2000: 1-18.

7. Department of Health and Human Services HRaSA, Healthcare Systems Bureau, Division of Transplantation. 2004 Annual Report of the US Organ Procurement and Transplantation Network and the Scientific Registry of Transplant Recipients: Transplant Data 1994 - 2003. Rockville, MD.

8. Chaudhary A, Shapiro R, Wijkstrom M (2013) Kidney TransplantationSurgical Techniques. ICU Care of Abdominal Organ Transplant Patients.

9. Morris P, Knechtle SJ (2013) Kidney transplantation-principles and practice: Elsevier Health Sciences.

10. Kher A, Mandelbrot DA (2012) The living kidney donor evaluation: focus on renal issues. Clin J Am Soc Nephrol 7: 366-371.

11. Gupta N, Raina P, Kumar A (2005) Laparoscopic donor nephrectomy. J Minim Access Surg 1: 155-164.

12. Nanidis TG, Antcliffe D, Kokkinos C, Borysiewicz CA, Darzi AW, et al. (2008) Laparoscopic versus open live donor nephrectomy in renal transplantation: a meta-analysis. Ann Surg 247: 58-70.

13. Salama AD, Womer KL, Sayegh MH (2007) Clinical transplantation tolerance: many rivers to cross. J Immunol 178: 5419-5423.

14. Denton MD, Magee CC, Sayegh MH (1999) Immunosuppressive strategies in transplantation. Lancet 353: 1083-1091.

15. Magee CC, Pascual M (2004) Update in renal transplantation. Arch Intern Med 164: 1373-1388.

16. Hricik DE (2002) Steroid-free immunosuppression in kidney transplantation: an editorial review. Am J Transplant 2: 19-24.

17. Webster AC, Playford EG, Higgins G, Chapman JR, Craig JC (2004) Interleukin 2 receptor antagonists for renal transplant recipients: a metaanalysis of randomized trials. Transplantation 77: 166-176.

18. Szczech LA, Berlin JA, Aradhye S, Grossman RA, Feldman HI (1997) Effect of anti-lymphocyte induction therapy on renal allograft survival: a meta-analysis. J Am Soc Nephrol 8: 1771-1777.

19. Wekerle T, Grinyó JM (2012) Belatacept: from rational design to clinical application. Transpl Int 25:139-150.

20. Crop MJ, Baan CC, Korevaar SS, Ijzermans JN, Alwayn IP, et al. (2009) Donor-derived mesenchymal stem cells suppress alloreactivity of kidney transplant patients. Transplantation 87: 896-906.
21. Chen YT, Sun CK, Lin YC, Chang LT, Chen YL, et al. (2011) Adiposederived mesenchymal stem cell Protects kidneys against ischemiareperfusion injury through suppressing oxidative stress and inflammatory reaction. J Transl Med 9: 51.

22. Casiraghi F, Perico N, Remuzzi G (2013) Mesenchymal stromal cells to promote solid organ transplantation tolerance. Curr Opin Organ Transplant 18: 51-58.

23. Puttarajappa C, Shapiro R, Tan HP (2012) Antibody-mediated rejection in kidney transplantation: a review. J Transplant 2012: 193724.

24. Wolfe RA, Ashby VB, Milford EL, Ojo AO, Ettenger RE, et al. (1999) Comparison of mortality in all patients on dialysis, patients on dialysis awaiting transplantation, and recipients of a first cadaveric transplant. $\mathrm{N}$ Engl J Med 341: 1725-1730.

25. Cecka JM (2002) The UNOS Renal Transplant Registry. Clin Transpl 2002: 1-20.

26. Mehrabi A, Wiesel M, Zeier M, Kashfi A, Schemmer P, et al. (2004) Results of renal transplantation using kidneys harvested from living donors at the University of Heidelberg. Nephrol Dial Transplant 19: iv48iv54.

27. Koo DD, Welsh KI, Mclaren AJ, Roake JA, Morris PJ, et al. (1999) Cadaver versus living donor kidneys: impact of donor factors on antigen induction before transplantation. Kidney Int 56: 1551-1559.

28. Lee S, Kim J, Shin M, Kim E, Moon J, et al. (2010) Comparison of outcomes of living and deceased donor kidney grafts surviving longer than 5 years in Korea. Transplant Proc 42: 775-777.

29. Koning OH, Ploeg RJ, van Bockel JH, Groenewegen M, van der Woude FJ, et al. (1997) Risk Factors for Delayed Graft Function in Cadaveric Kidney Transplantation: A Prospective Study of Renal Function and Graft Survival after Preservation with University of Wisconsin Solution in Multi-Organ Donors. European Multicenter Study Group. Transplantation 63: 1620-1628.

30. Van Arendonk KJ, James NT, Orandi BJ, Garonzik-Wang JM, Smith JM, et al. (2013) Order of Donor Type in Pediatric Kidney Transplant Recipients Requiring Retransplantation. Transplantation 96: 487-493.

31. Gascó B, Revuelta I, Sánchez-Escuredo A, Blasco M, Cofán F, et al. (2014) Long-term mycophenolate monotherapy in human leukocyte antigen (HLA)-identical living-donor kidney transplantation. Transplant Res 3:

32. Davis CL, Delmonico FL (2005) Living-donor kidne y transplantation: a review of the current practices for the live donor. J Am Soc Nephrol 16: 2098-2110.

33. Goetti R, Baumueller S, Alkadhi H, Clavien PA, Schiesser M, et al. (2013) Diagnostic Performance of a Non Contrast Enhanced Magnetic Resonance Imaging Protocol for Potential Living Related Kidney Donors. Acad Radiol 20: 393-400.

34. Sattar A, Naeem S, Ali A, Akhtar M, Rizvi A, et al. (2014) Evaluation of Number of Renal Arteries in Live Related Renal Donors by CT Angiography and Conventional Angiography. International Journal of Endorsing Health Science Research 2: 1-15.

35. Simforoosh N, Gooran S, Tabibi A, Bassiri A, Ghraati MR (2011) Cadaver transplantation in Recent Era: Is Cadaveric Graft Survival Similar to Living Kidney Transplantation? Int J Organ Transplant Med 2: 167-170.

36. Purnell TS, Powe NR, Troll MU, Wang NY, Haywood C Jr, et al. (2013) Measuring and explaining racial and ethnic differences in willingness to donate live kidneys in the United States. Clin Transplant 27: 673-683.

37. Looze KD, Shroff S (2012) Can presumed consent overcome organ shortage in India? Lessons from the Belgian experience. Natl Med J India 25: $168-171$. 